\title{
AN EFFECTIVE THERMAL TECHNOLOGY FOR THE DETOXIFICATION OF THE MSW FLY ASH
}

\author{
Rui Lima \\ IPB - Instituto Politécnico de Bragança \\ Estig, Gab. 23 \\ Campus de Santa Apolónia \\ Apartado 134 5301-857 Bragança \\ Portugal \\ Email: ruimec@ipb.pt \\ Marcos Saloca \\ ALBRA \\ Departamento da Qualidade \\ Lugar de Alagoa, Este-S. Mamede \\ Apt. 10 4711-909 Braga \\ Portugal
}

\begin{abstract}
The increasing public concern of potential health problems, due to improper waste disposal practices as well as the introduction of landfill taxes, have induced the practice of incineration. Presently, all UK incinerators have to meet very strict emission levels. In this way, the generated fly ash residues have to be managed very carefully as they are enriched with toxic organic micropollutants and heavy metals.

The aim of the present work is to describe a novel thermal technology, known as the ash detoxification process, that has shown success not only in the destruction of its toxic organic components, but also in the fixation of its heavy metal content to form an unleachable material.
\end{abstract}

KEY WORDS : thermal technologies, heat regeneration, incineration, fly ash residues, the ash detoxification process. 


\section{INTRODUCTION}

The pollution control technology has developed considerably in the last ten years. Therefore, there are several reliable systems to remove almost all polluting emissions from the flue gas stream. The combination of those systems with an efficient combustion control is the key to obtain almost zero micropollutants emissions to atmosphere. However, the bottom and fly ash residues generated by such systems pose a significant disposal problem.

The disposal of these toxic residues in landfills has been subject to increasingly stringent controls mainly due to the environmental concerns about the presence of dioxins and heavy metals in the ash. As a result, many researchers around the world have developed technologies in order not only to immobilise the metals but also to destroy its toxic organic components. However, most of these are at the pilot scale or at semicommercial demonstration stage. [1, 2, 3]

In recent years the Sheffield University Waste Incinerator Centre (SUWIC) has been carrying out extensive research in order to develop an effective novel sintering technology for the detoxification of the fly ash. The technology is based on a regenerative heating concept in order to achieve high thermal efficiency.[3]

P.H. Lee showed that the sintering processing operating at $850^{\circ} \mathrm{C}$ is capable of immobilising the heavy metals present in the fly ash. For instance, more than $86 \%$ of $\mathrm{Pb}$ leachability reduction was achieved. This improvement is due to the formation of stable oxide matrices.[4]

On the other hand, David Ward [3] carried out a study into the destructive effects of the sintering process with respect to the dioxin content of municipal waste incinerator fly ash. Ward showed that this process cause significant reduction of dioxin concentrations in fly ash.

It is suggested that this process is capable to covert toxic fly ash from incinerators into a material which can be used in civil engineering applications.[3, 4, 5] The figure 1 shows an overview of the experimental fly ash detoxification pilot rig.



Fig.1 - Full scale of the experimental fly ash detoxification pilot rig. [6] 


\section{THE ASH DETOXIFICATION PROCESS}

\subsection{DESCRIPTION OF THE SYSTEM}

The system is based on a twin bed regenerative burner. While the first of the two burner uses cold air fed to the base of its regenerator, exhaust gas is drawn through the second burner and down into its associated regenerator to preheat the packing bed and then discharged to the atmosphere. When the regenerator being heated is sufficiently charged, the reversing system operates so that the cold air flows to the just heated regenerator and is preheated. The main advantage of this concept is the reduction of fuel consumption. [4, 5, 7] According to some researchers, this concept can achieve efficiencies of 80 to $90 \%$. [7, 8, 9]

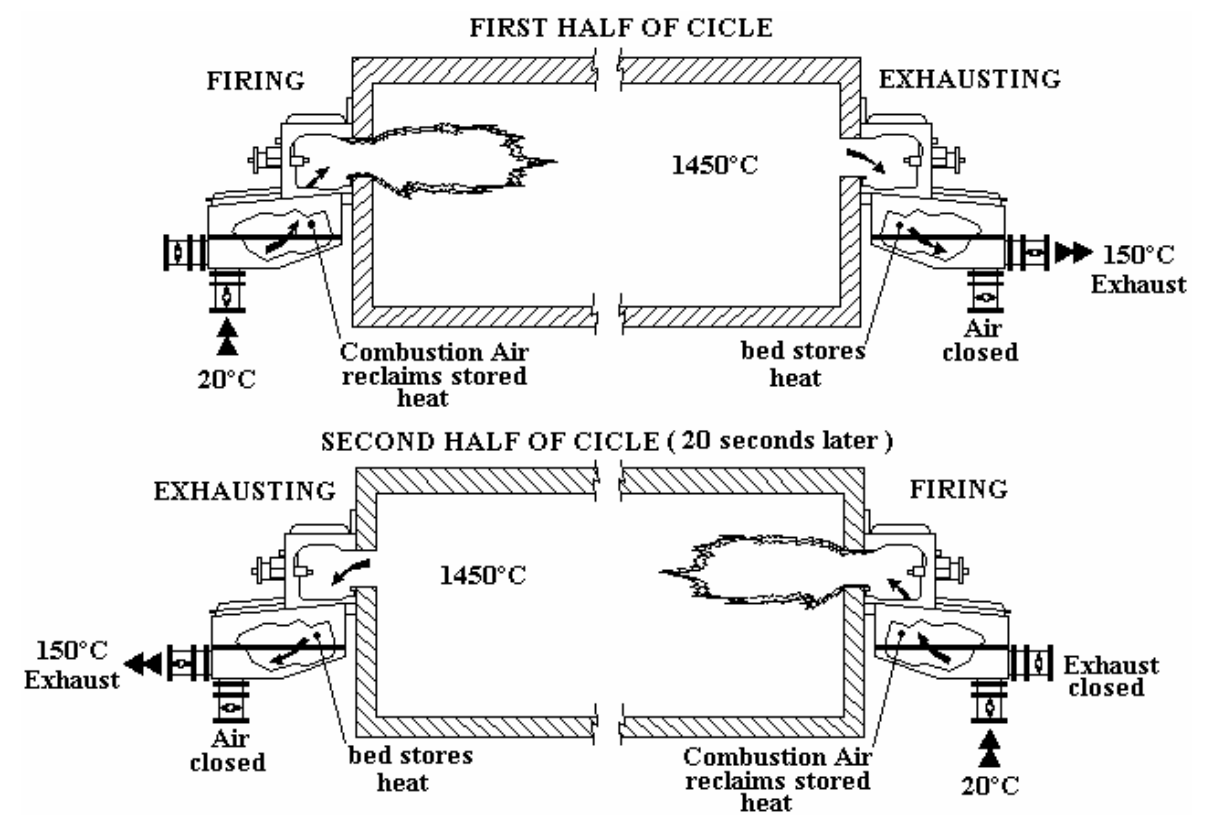

Fig. 2 - Cycle operation of a twin bed regenerative burner, adapted from [7].

The ash-sintering rig comprises a pair of a 300KW Regenerative Ceramic Burners (RCB) which can provide enough heat to sinter about $0.2 \mathrm{Kg} / \mathrm{s}$ of fly ash. Its main components are: a pair of pebble bed, a safety equipment, pneumatic operated butterfly valves, a fuel-air ratio control and associated controls, a pair of symmetrical cyclones, a air draught fan and a screw feeder.

A schematic diagram of the experimental ash detoxification rig is shown in figure 3 As it is illustrated, the fly ash is fed into the burner 1 and heated to a temperature of about $850^{\circ} \mathrm{C}$ (the sintering temperature of the fly ash) [4]. As a result, the ash particles are separated in the cyclones, due to centrifugal forces, and the combustion products are drawn through the burner 2 and passed through its associated regenerator. Before exiting the system, exhaust gases are passed through a pebble bed where heat is recuperated. When the regenerator 2 is sufficiently charged, the reversing system operates so that the combustion air flows to the just heated regenerator and is preheated. Hence, the fly ash is now introduced into the burner 2 and the combustion products leave the cyclone via unit 1 (burner 1, regenerator 1). Worthy of note, the fact that the reversal valves are activated by 
a logic control unit, which allows the combustion air to be fed either to burner 1 or 2 but never both together.

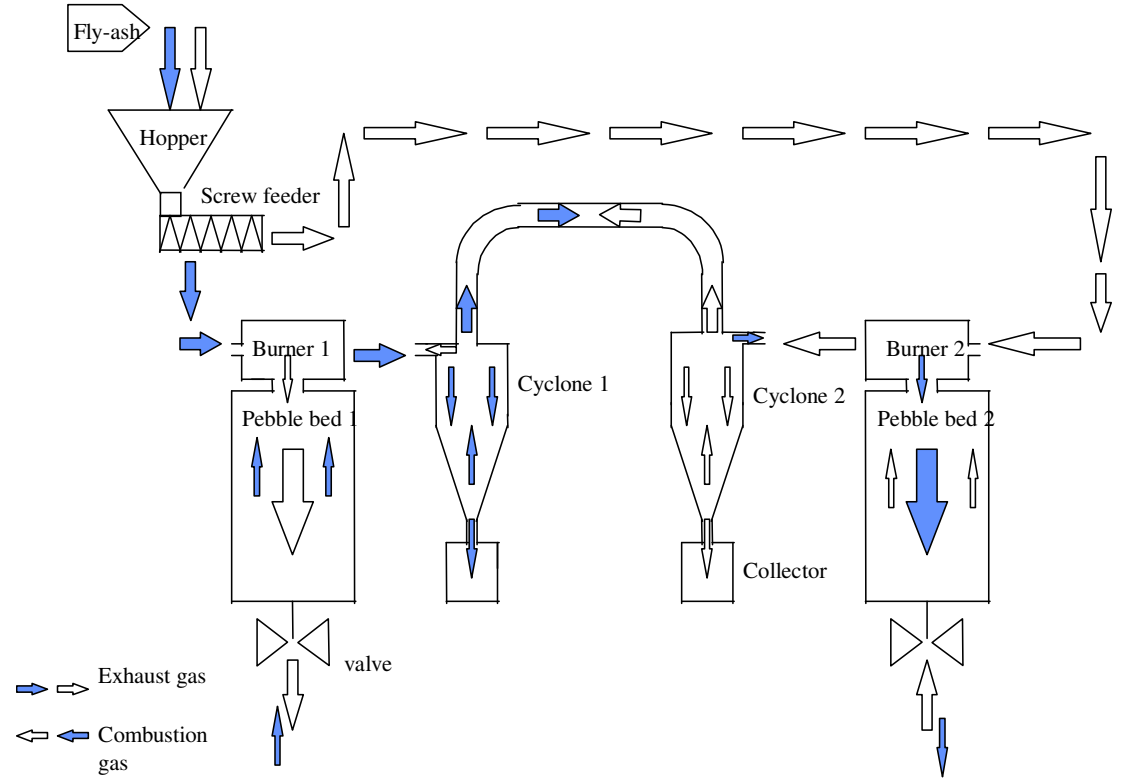

Fig.3 - Schematic diagram of the experimental ash detoxification rig.[4]

\subsection{SINTERING PROCESS}

The agglomeration of particles under heating is known as sintering. P.H Lee [4] has observed that the ash particles start to agglomerate together at temperatures of about $850^{\circ} \mathrm{C}$. In the figure 4 it is possible to observe the particles agglomeration after the thermal treatment.

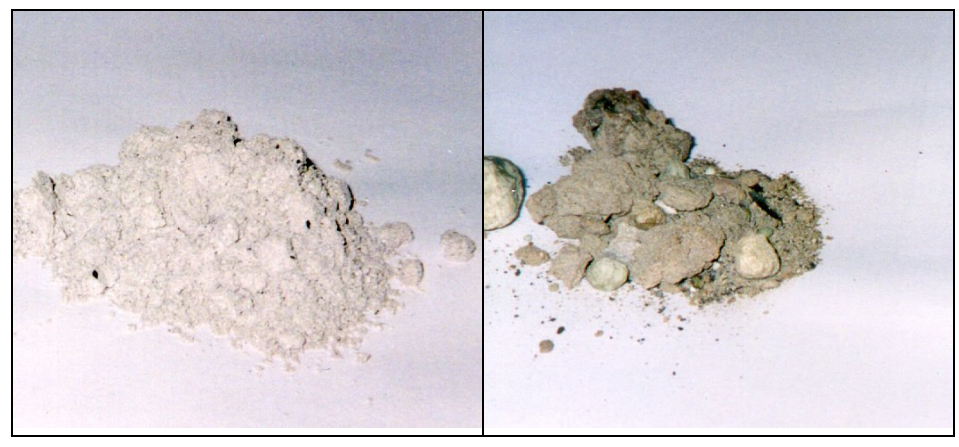

a)

b)

Fig.4 - a) Fly ash from MSWI, before thermal treatment. b) Sintered fly ash. [6]

The sintering temperature of about $850^{\circ} \mathrm{C}$ is significantly lower than the ash melting point, which is about $1300^{\circ} \mathrm{C}$. It should be noted that the temperature inside the cyclones must be below $1300^{\circ} \mathrm{C}$, since this temperature is the melting point of the fly ash. Hence, if the fly ash starts to melt, it may stick to the walls and cause a build up.[4] 


\subsection{CYCLONE}

The symmetrical twin cyclone was selected because of the ability to handle fine particles, the good contact between the gas and the solids and the complete separation of the end products [4]. Accordingly, the cyclone must provide not only enough time to sinter the ash but also ash particles must be separated from the hot gas of combustion. According to a computational fluid modelling of the cyclone, residence times of about 0.3 seconds were obtained.[4] The appropriate ratios of cyclone dimensions are shown in figure 5.



Fig.5 - Schematic diagram of the cyclone.[4]

\section{CONCLUSION}

Presently, fly ash is classified as a hazardous material, which is being landfilled at very high price. The ash detoxification process seems to convert the hazardous material to a non-hazardous one, which can either be landfilled at a very low cost or used in the construction industry. According to the present work, this new thermal technology seems to be a very economic and effective method for the detoxification of incinerator fly ash and, therefore, a promising way of dealing with toxic ash.

\section{REFERENCES}

[1] Williams, P., "Waste Treatment and Disposal", West Sussex: John Wiley and Sons Ltd, 1888.

[2] Royal Commission on Environmental Pollution, "Seventeenth Report Incineration of Waste", HMSO, London, 1883. 
[3] Ward, D., "An Investigation Into The Detoxification Of Dioxin Contained Fly Ash By Energy Efficient Sintering." MSc(Res) Materials, Structures and Systems Engineering, Sheffield University, Department of Chemical and Process Engineering, Sheffield, 1888.

[4] Lee, Poh Hoon; "Development of a Novel Technology for the Detoxification of Fly Ash Produced by Waste Incineration Industry", PhD Thesis, Sheffield University, Department of Chemical and Process Engineering, Sheffield, April, 1888.

[5] Lee, P. et al.; "Characterization, Decontamination and Health Effects of Fly-Ash from Waste Incinerators" Environmental Progress, Vol.17, No4, Winter 1888.

[6] Lima, R., "The Detoxification of Fly Ash from MSWI" MSc(Eng) Environmental and Energy Engineering, Sheffield University, Department of Chemical and Process Engineering, Sheffield, 2000.

[7] Commission of the European Communities, "European Seminar On Improved Technologies For The Rational Use Of Energy in the Glass Industry", Fachinfromationszentrum Karlsruhe, 1882.

[8] Lettington, C.; "High Temperature Regeneration", PhD Thesis, Sheffield University, Department of Fuel Technology and Chemical Engineering, Sheffield, May, 1865.

[9] Lee, P. H.; "The Energy Efficient Thermal Detoxification of Fly Ash", International Conference on Incineration and Thermal Treatment Technologies (IT3), Salt Lake City, USA, May, 1888. 